\title{
Proteome profiling of heat, oxidative, and salt stress responses in Thermococcus kodakarensis KOD1
}

\section{OPEN ACCESS}

Edited by:

Syed Gulam Dastager, National Chemical Laboratory, India

Reviewed by:

R. Thane Papke,

University of Connecticut, USA

Takuro Nunoura

Japan Agency for Marine-Earth

Science and Technology, Japan

*Correspondence:

Baolei Jia,

Department of Life Science,

Chung-Ang University,

Seoul 156-756, South Korea

baoleijia@cau.ac.kr

jiabaolei@hotmail.com;

Gang-Won Cheong,

Division of Applied Life Sciences

and Research Institute of Natural

Science, Gyeongsang National

University, Jinju 660-701.

South Korea

gwcheong@gnu.ac.kr

tThese authors have contributed equally to this work.

Specialty section:

This article was submitted to

Extreme Microbiology,

a section of the journal

Frontiers in Microbiology

Received: 30 March 2015

Accepted: 02 June 2015

Published: 19 June 2015

Citation:

Jia B, Liu J, Van Duyet L, Sun Y, Xuan YH and Cheong G-W (2015)

Proteome profiling of heat, oxidative, and salt stress responses

in Thermococcus kodakarensis

KOD1.

Front. Microbiol. 6:605.

doi: 10.3389/fmicb.2015.00605

\section{Baolei Jia ${ }^{1,2 *}$, Jinliang Liu ${ }^{3 \dagger}$, Le Van Duyet ${ }^{2 \dagger}$, Ying Sun ${ }^{3 \dagger}$, Yuan H. Xuan ${ }^{4}$ and Gang-Won Cheong ${ }^{2 *}$}

${ }^{1}$ Department of Life Science, Chung-Ang University, Seoul, South Korea, ${ }^{2}$ Division of Applied Life Sciences and Research Institute of Natural Science, Gyeongsang National University, Jinju, South Korea, ${ }^{3}$ College of Plant Sciences, Jilin University, Changchun, China, ${ }^{4}$ College of Plant Protection, Shenyang Agricultural University, Shenyang, China

The thermophilic species, Thermococcus kodakarensis KOD1, a model microorganism for studying hyperthermophiles, has adapted to optimal growth under conditions of high temperature and salinity. However, the environmental conditions for the strain are not always stable, and this strain might face different stresses. In the present study, we compared the proteome response of $T$. kodakarensis to heat, oxidative, and salt stresses using two-dimensional electrophoresis, and protein spots were identified through MALDI-TOF/MS. Fifty-nine, forty-two, and twenty-nine spots were induced under heat, oxidative, and salt stresses, respectively. Among the up-regulated proteins, four proteins (a hypothetical protein, pyridoxal biosynthesis lyase, peroxiredoxin, and protein disulphide oxidoreductase) were associated with all three stresses. Gene ontology analysis showed that these proteins were primarily involved metabolic and cellular processes. The KEGG pathway analysis suggested that the main metabolic pathways involving these enzymes were related to carbohydrate metabolism, secondary metabolite synthesis, and amino acid biosynthesis. These data might enhance our understanding of the functions and molecular mechanisms of thermophilic Archaea for survival and adaptation in extreme environments.

Keywords: proteome, stress responses, Thermococcus, archaea, metabolic pathway

\section{Introduction}

Thermococcus kodakarensis KOD1 is a hyperthermophilic anaerobic archaeon, isolated from a solfatara $\left(102^{\circ} \mathrm{C}, \mathrm{pH}\right.$ 5.8) on the shore of Kodakara Island, Kagoshima, Japan (Morikawa et al., 1994). The environmental conditions are not always conducive to steady growth, as fluctuations in temperature regime, fluid flux, and carbon substrate supply create a spatial and temporal mosaic of microenvironments (Edgcomb et al., 2007). The different environmental conditions over time have facilitated the evolution of Archaea for adaptation to extreme environments, and indeed, these bacteria experience difficulties acclimating to less extreme conditions (Reed et al., 2013). T. kodakarensis KOD1 senses the environment and responds to changing environmental conditions (Izumi et al., 2001). Many proteins have been reported to play important roles in cellular protection against different stresses. For example, osmotically inducible protein C (OsmC) from $T$. kodakarensis plays a role in cellular defense against oxidative stress induced through exposure to hyperoxides or elevated 
osmolarity (Park et al., 2008). T. kodakarensis also possesses four prefoldin genes, encoding two alpha subunits (pfdA and $\mathrm{pfdC}$ ) and two beta subunits (pfdB and pfdD) of prefoldins on the genome. The $\mathrm{PfdA} / \mathrm{PfdB}$ complex functions at all growth temperatures, while the $\mathrm{PfdC} / \mathrm{PfdD}$ complex contributes to survival in high-temperature environments (Danno et al., 2008). Proteins involved in oxidative stress were well studied in Pyrococcus, which belong to the same order Thermococcales, along with $T$. kodakarensis KOD1. In Pyrococcus horikoshii, a significant increase of a $25 \mathrm{kDa}$ alkyl hydroperoxide reductase (PH1217) was observed when the microorganism was cultivated under aerobic conditions (Kawakami et al., 2004). P. furiosus is surprisingly tolerant to oxygen, growing well in the presence of $8 \%(\mathrm{vol} / \mathrm{vol}) \mathrm{O}_{2}$. Superoxide reductase (SOR) and putative flavodiiron protein A play important roles in resisting $\mathrm{O}_{2}$ (Thorgersen et al., 2012). Most cellular stress responses are highly conserved cellular defense mechanisms for protection against sudden environmental changes or frequent fluctuations in environmental factors (Feder and Hofmann, 1999). The cellular stress response has been associated with essential aspects of protein and DNA processing and stability in all three superkingdoms of life: Archaea, Bacteria, and Eukarya (Kültz, 2003). In Archaea, T. kodakarensis has emerged as a premier model system for studies of archaeal biochemistry, genetics, and hyperthermophily (Hileman and Santangelo, 2012). However, the current knowledge of the stress proteome of $T$. kodakarensis, i.e., the proteins expressed in response to cellular stress, remains fragmented.

Proteomics techniques are powerful tools for the identification of the quantitative changes in protein expression in response to stress exposure in cells, tissues or biological fluids. The first proteomics studies of thermophilic Archaea, involving the proteome of Sulfolobus solfataricus P2, were reported Chong and Wright (2005). Since then, the proteomics analysis of Thermococcus was conducted in 2009, which characterized the abundant expression of Thermococcus onnurineus NA1 proteins in enriched medium (Kwon et al., 2009). Recent developments in proteomics studies on extremophiles have provided unique information on the physiological characteristics required for adaptation to extreme conditions. For example, formate is used in gluconeogenesis and carbon monoxide is converted to carbon dioxide and assimilated into organic carbon in T. onnurineus NA1 (Yun et al., 2014).

In the present study, we simultaneously analyzed alterations in protein expression during heat, oxidative, and salt stresses based on two-dimensional (2-D) gel electrophoresis. We conducted proteomics analyses using matrix-assisted laser desorption ionization-time of flight/mass spectrometry (MALDI-TOF/MS) to identify the major proteins. The completed genome of T. kodakarensis KOD1 has facilitated the use of proteomics analyses under different stress conditions. The aim of the present study was to highlight the molecular adaptation mechanisms of T. kodakarensis KOD1 and reveal both common and distinct response pathways involved in the adaptation of this species to heat, salt, and oxidative stress.

\section{Materials and Methods}

\section{Organism and Cell Culture}

The T. kodakarensis strain KOD1 was obtained from the Japan Collection of Microorganisms (JCM). The cells were cultured in JCM medium $280^{1}$.

\section{Heat, Oxidative, and Salt Stress Procedure}

Culture of T. kodakarensis KOD1were carried out in triplicate in $40 \mathrm{~mL}$ cultures in $50 \mathrm{~mL}$ serum bottles at $85^{\circ} \mathrm{C}$ anaerobically on a shaking incubator $(150 \mathrm{rpm})$. For heat stress, the cells in the mid-log phase were shocked by exposure to $95^{\circ} \mathrm{C}$ and incubating for $4 \mathrm{~h}$. For oxidative stress, the cells in the midlog phase were cultured under aerobic conditions after adding oxygen $(5 \mathrm{~L} / \mathrm{min})$ for $30 \mathrm{~min}$. Each culture was maintained at $85^{\circ} \mathrm{C}$ for $4 \mathrm{~h}$. For osmotic stress, T. kodakarensis KOD1 was grown until the mid-log phase and the cells were salt shocked after adding a final concentration of $1 \mathrm{M} \mathrm{NaCl}$ to the medium and incubating for $4 \mathrm{~h}$. The cells treatment for $1 \mathrm{~h}$ was harvested through centrifugation at $12,000 \mathrm{rpm}$ for $10 \mathrm{~min}$ at $4^{\circ} \mathrm{C}$ for two-dimensional gel electrophoresis (2-DE). Survival of the cells was estimated by the three-tube most probable number method per 30 min period after exposure to stress. Samples were diluted serially in growth medium, and cultures were incubated at $85^{\circ} \mathrm{C}$.

\section{2-DE}

The cells were washed with 1X PBS (the salt stress cells including control were washed four times and others were washed twice), and the total proteins were solubilized in lysis buffer $(8 \mathrm{M}$ urea, 4\% CHAPS, $40 \mathrm{mM}$ Tris, $100 \mathrm{mM}$ DTT, and 0.5\% carrier ampholyte) for $20 \mathrm{~min}$. The soluble proteins were separated through centrifugation at $40,000 \mathrm{rpm}$ for $1 \mathrm{~h}$ at $4^{\circ} \mathrm{C}$. The soluble protein concentration was determined using a standard Bradford method (Bradford, 1976).

Isoelectric focusing (IEF) was conducted using the IPGphor/IsoDalt system (Bio-Rad, Hercules, CA, USA) at $20^{\circ} \mathrm{C}$. IPG gel strips system (Bio-Rad., Hercules, CA, USA) were rehydrated in swelling solution (7 M urea, $2 \mathrm{M}$ thiourea, 2\% CHAPS, $100 \mathrm{mM}$ DTT, 0.5\% IPG buffer system (Bio-Rad, Hercules, CA, USA) and bromophenol blue containing $100 \mathrm{mg}$ of protein for $12 \mathrm{~h}$ at $20^{\circ} \mathrm{C}$, and subsequently, IEF was performed for $1 \mathrm{~h}$ at $200 \mathrm{~V}, 1 \mathrm{~h}$ at $500 \mathrm{~V}, 1 \mathrm{~h}$ at $1000 \mathrm{~V}, 1 \mathrm{~h}$ at $1000 \mathrm{~V}$, $30 \mathrm{~min}$ at $8000 \mathrm{~V}$, and $45000 \mathrm{Vh}$. The IPG strips were equilibrated for $15 \mathrm{~min}$ in Solution I $(50 \mathrm{mM}$ Tris- $\mathrm{HCl}, \mathrm{pH} \mathrm{8.8,6} \mathrm{M}$ urea, $30 \%$ glycerol, $2 \%$ SDS, $10 \mathrm{mg} / \mathrm{mL}$ DTT, and bromophenol blue), followed by $15 \mathrm{~min}$ in Solution II (50 mM Tris- $\mathrm{HCl}, \mathrm{pH}$ 8.8, $6 \mathrm{M}$ urea, $30 \%$ glycerol, $2 \%$ SDS, $2 \%$ iodoacetamide, and bromophenol blue). For the second dimension, vertical slab gels were used. The $12 \%$ SDS gels were prepared, and an equilibrated IPG gel strip was laid on top of the gel filled with $0.5 \%$ agarose solution. Electrophoresis was performed at $5 \mathrm{~mA} / \mathrm{cm}$ for $1 \mathrm{~h}$ at room temperature, followed by $10 \mathrm{~mA} / \mathrm{cm}$ until the dye front reached the bottom of the gel. The proteins were detected through silver staining.

\footnotetext{
${ }^{1}$ http://www.jcm.riken.jp/cgi-bin/jcm/jcm_grmd?GRMD = 280\&MD_NAME
} 


\section{Protein Visualization and Image Analysis}

The stained gels were scanned and digitized using a Duoscan scanner (Agfa, Trenton, NJ, USA; Bio-Rad, Hercules, CA, USA). After background subtraction, normalization, and matching, the spot volumes in gels from each treated-cell sample were compared with the matched spot volumes in gels from control cells. Comparison of the test spot volumes with the corresponding standard spot volumes yielded a standardized abundance for each matched spot, and the values were averaged across triplicates for each experimental condition. Statistical analysis was performed to select the matching spots across all images, including spots displaying $a \geq 1.5$ average-fold increases in abundance between conditions and spots with $P<0.05$. Spots differentially and markedly overexpressed were excised.

\section{Protein Identification}

The Voyager-DE ${ }^{\mathrm{TM}}$ STR Biospectrometry Workstation (Applied Biosystems, Foster City, CA, USA) was used for MALDITOF/MS. The desired gel pieces were carefully excised, destained, and in-gel digested using trypsin. Briefly, the excised-gel pieces were washed with water for $2 \times 15 \mathrm{~min}$, followed by an additional wash with water/acetonitrile $(1: 1)$ for $2 \times 15 \mathrm{~min}$. After removing all liquid, acetonitrile was added to cover the gel pieces. Acetonitrile was removed after the gel pieces were shrunk. The gel pieces were rehydrated in $0.1 \mathrm{M}$ ammonium bicarbonate for $5 \mathrm{~min}$, and subsequently incubated for $15 \mathrm{~min}$ with an equal volume of acetonitrile. After removing all liquid, the gel pieces were dried in a vacuum centrifuge for $20 \mathrm{~min}$. The gel pieces were swollen in $10 \mathrm{mM}$ DTT/0.1 M ammonium bicarbonate and incubated for $45 \mathrm{~min}$ at $56^{\circ} \mathrm{C}$, followed by cooling at RT. After removing the excess liquid, the same volume of freshly prepared $55 \mathrm{mM}$ iodoacetamide in $0.1 \mathrm{M}$ ammonium bicarbonate was added, followed by incubation in the dark for $30 \mathrm{~min}$ at room temperature. The iodoacetamide solution was removed, and the gel pieces were incubated in $30 \mathrm{~mL}$ of $0.1 \mathrm{M}$ ammonium bicarbonate for $5 \mathrm{~min}$, and subsequently further incubated for $15 \mathrm{~min}$ with an equal volume of acetonitrile. After an additional incubation with ammonium carbonate/acetonitrile, the gel pieces were dried in a vacuum centrifuge for $20 \mathrm{~min}$, rehydrated in digestion buffer and placed on ice for $45 \mathrm{~min}$. The buffer was replaced with $20 \mathrm{~mL}$ of digestion buffer with trypsin $\left(12,500 \mu \mathrm{g} \mathrm{mL}^{-1}\right)$. After overnight digestion at $37^{\circ} \mathrm{C}$, a sufficient volume of $25 \mathrm{mM}$ ammonium bicarbonate was added to cover the gel pieces and incubated for $15 \mathrm{~min}$. The same volume of acetonitrile was added and incubated for $15 \mathrm{~min}$, followed by the addition of $5 \%$ formic acid/acetonitrile (1:1) to the recovered supernatant and incubation for $30 \mathrm{~min}$. After repeating this step, all the extracts were dried in a vacuum centrifuge for 1-2 h. The dried peptide was dissolved in $20 \mathrm{~mL}$ of $5 \%$ formic acid and sonicated for $5 \mathrm{~min}$ in a water bath sonicator. The peptide sample $(2 \mathrm{~mL})$ with standard calibrant $(1 \mathrm{~mL})$ was mixed with $2 \mathrm{~mL}$ of a $2: 1: 1(\mathrm{v}: \mathrm{v}: \mathrm{v})$ matrix mixture containing matrix solution (20 mg a-cyano-4-hydroxycinnamic acid/1 mL acetone):nitrocellulose solution (20 mg nitrocellulose/1 $\mathrm{mL}$ acetone): 2-propanol. Two microliters of sample was loaded onto a MALDI plate, dried for $30 \mathrm{~min}$ at room temperature, rinsed with $5 \mathrm{~mL}$ of $5 \%$ formic acid, and washed with $5 \mathrm{~mL}$ of water.
After drying at room temperature, the plate probe was inserted into a MALDI mass spectrometer. For protein identification, we performed searches in the NCBInr, Swiss-Prot/TrEMBL, and MSDB sequence databases using MS-Fit ${ }^{2}, \mathrm{Mascot}^{3}$, and ExPASy ${ }^{4}$. The complete experiment was repeated three times, including cell growth, proteome purification, $2-\mathrm{DE}$, and protein identification.

\section{Agar Plate Bioassay}

Polymerase chain reaction (PCR) using T. kodakarensis KOD1 genomic DNA as a template was performed to isolate TK0108, TK0217, TK0537, and TK1085 using the following oligonucleotide primers listed in supplementary Table 1. The PCR products and the pET28a vector were digested by the restriction enzymes. The ligation products were transformed into Escherichia coli BL21 (DE3) cells by electroporation and confirmed by sequencing. E. coli cells containing the four recombinant plasmids were named as pET28a-TK0108, pET28aTK0217, pET28a-TK0537, and pET28a-TK1085, respectively. The E. coli cells were cultured in $10 \mathrm{~mL}$ of $\mathrm{LB}$ broth containing $30 \mu \mathrm{g} \mathrm{mL}^{-1}$ kanamycin at $37^{\circ} \mathrm{C}$ for $3 \mathrm{~h}$. When the $\mathrm{OD}_{600}$ reached 0.7 , isopropyl- $\beta$-D-thiogalactopyranoside (IPTG) was added to a final concentration of $1 \mathrm{mM}$ to induce protein expression. After $4 \mathrm{~h}$ of culture with shaking, the $\mathrm{OD}_{600}$ were adjusted to 0.5 and the protein expression were checked by SDS-PAGE. Petri plate-based dilution bioassays were performed after the cells were treated at $50^{\circ} \mathrm{C}$ for $20 \mathrm{~min}$ or the cells were spotted onto LB plates with $5 \mathrm{mM} \mathrm{H}_{2} \mathrm{O}_{2}$ and $1 \mathrm{M} \mathrm{NaCl}$, respectively. The images were taken after incubation at $37^{\circ} \mathrm{C}$ for $12 \mathrm{~h}$. This assay was performed in triplicate for three times and the representative images were shown.

\section{Data Analysis}

Gene ontology (GO) enrichment was performed using BLAST2GO (Conesa and Gotz, 2008). The Kyoto Encyclopedia of Genes and Genomes (KEGG) was used to determine the position of the identified proteins in respective pathways (Kanehisa and Goto, 2000). Protein-protein interactions were predicted using STRING set at high confidence (Franceschini et al., 2013), and Cytoscape was used for network visualization (Shannon et al., 2003). The protein function was predicted by BLAST (Altschul et al., 1997), SMART (Roy et al., 2010), and I-TASSER (Letunic et al., 2015).

\section{Result}

\section{Cell Growth, Proteome Analysis, and Protein Identification}

Thermococcus kodakarensis KOD1 has been reported to strictly anaerobic. Temperature range of growth is $60-100^{\circ} \mathrm{C}$, with an optimum of approximately $85^{\circ} \mathrm{C}$. Range of $\mathrm{NaCl}$ concentration allowing growth is between 0.17 and $0.86 \mathrm{M}$, with an optimum of $0.52 \mathrm{M}$ (Atomi et al., 2004). Further research showed that

\footnotetext{
${ }^{2}$ http://prospector.ucsf.edu

${ }^{3} \mathrm{http}: / /$ www.matrixscience.com

${ }^{4}$ http://www.expasy.org
} 
TABLE 1 | List of up-regulated proteins under heat stress in Thermococcus kodakarensis KOD1.

\begin{tabular}{|c|c|c|c|c|c|c|c|c|}
\hline No & Protein name & Protein ID & $\operatorname{SC}(100 \%)^{a}$ & Fold change & $\mathbf{p l}^{\mathbf{b}}$ & $\mathrm{pl}^{\mathrm{c}}$ & $M w^{d}$ & $\mathbf{M w}^{\mathbf{e}}$ \\
\hline 1 & Thermosome alpha subunit & TK0678 & 48 & 3.2 & 4.84 & 4.8 & 59.12 & 59.2 \\
\hline 2 & ATP-dependent glucokinase & TK1110 & 19 & 2.1 & 5.52 & 5.6 & 50.70 & 50.0 \\
\hline 3 & Aspartyl - tRNA synthetase & TK0492 & 17 & 1.6 & 5.35 & 5.4 & 50.88 & 51.5 \\
\hline 4 & Hypothetical protein & TK0300 & 16 & 2.5 & 5.76 & 5.7 & 50.80 & 51.0 \\
\hline 5 & Ornithine carbamoyltransferase & TK0871 & 28 & 2.2 & 5.76 & 5.7 & 35.02 & 35.0 \\
\hline 6 & Probable transcription regulator & TK0471 & 43 & 2.9 & 6.01 & 6.5 & 30.81 & 31.0 \\
\hline 7 & RNA - binding protein & TK2097 & 15 & 2.1 & 6.02 & 5.5 & 18.03 & 18.0 \\
\hline 8 & Hypothetical protein & TK1561 & 26 & 2.6 & 5.32 & 5.4 & 21.77 & 23.0 \\
\hline 9 & 6,7-dimethyl-8-ribityllumazine synthase & TK0429 & 25 & 2.8 & 5.70 & 5.7 & 15.69 & 16.0 \\
\hline 10 & Hypothetical protein & TK0108 & 61 & 1.6 & 4.99 & 5.0 & 22.39 & 23.0 \\
\hline 11 & Cobalamin adenosyltransferase & TK1045 & 29 & 3.1 & 6.19 & 6.3 & 19.26 & 19.0 \\
\hline 12 & 2-dehydropantoate 2-reductase & TK1968 & 37 & 3.3 & 4.43 & 4.5 & 34.03 & 34.5 \\
\hline 13 & Hypothetical protein & TK1937 & 17 & 2.5 & 4.82 & 5.0 & 16.36 & 17.5 \\
\hline 14 & $N$-acetyltransferase & TK0232 & 41 & 3.2 & 5.76 & 5.8 & 31.78 & 32.0 \\
\hline 15 & Hypothetical protein MJ0668 & TK0823 & 24 & 3.0 & 6.53 & 6.7 & 10.13 & 10.0 \\
\hline 16 & Predicted exonuclease & TK0458 & 18 & 2.5 & 6.15 & 6.4 & 20.05 & 20.0 \\
\hline 17 & ABC-type maltodextrin-binding periplasmic component & TK1771 & 15 & 3.2 & 4.56 & 4.5 & 49.44 & 51.5 \\
\hline 18 & Thermosome beta subunit & TK2303 & 36 & 3.1 & 4.86 & 4.8 & 59.13 & 60.2 \\
\hline 19 & Sugar-phosphate nucleotidyltransferase & TK0955 & 19 & 2.5 & 5.15 & 5.2 & 46.80 & 47.7 \\
\hline 20 & Acyl-CoA synthetase & TK0944 & 8 & 3.3 & 5.51 & 5.7 & 51.83 & 50.9 \\
\hline 21 & Hypothetical protein & TK0077 & 28 & 1.9 & 4.94 & 5.1 & 5.34 & 5.4 \\
\hline 22 & Zinc-dependent protease & TK0689 & 31 & 3.8 & 5.20 & 5.2 & 48.52 & 49.0 \\
\hline 23 & ATPase, ParA/MinD family & TK0701 & 42 & 3.7 & 4.81 & 4.9 & 31.93 & 30.9 \\
\hline 24 & Hypothetical protein & TK1972 & 15 & 1.6 & 4.89 & 4.9 & 39.80 & 40.0 \\
\hline 25 & Glycine cleavage system protein $\mathrm{P}$ & TK1379 & 38 & 2.3 & 5.51 & 5.5 & 55.96 & 56.2 \\
\hline 26 & Methionine synthase ॥ & TK1447 & 12 & 2.6 & 5.90 & 5.9 & 35.25 & 35.0 \\
\hline 27 & Deoxyribose-phosphate aldolase & TK2104 & 27 & 2.3 & 5.18 & 5.2 & 24.49 & 26.0 \\
\hline 28 & Metallophosphoesterase & TK0547 & 19 & 2.6 & 5.22 & 5.3 & 24.12 & 23.0 \\
\hline 29 & Protein disulphide oxidoreductase & TK1085 & 39 & 3.8 & 4.72 & 4.8 & 25.28 & 25.6 \\
\hline 30 & Deblocking aminopeptidase & TK0781 & 31 & 1.9 & 5.46 & 5.5 & 38.27 & 38.5 \\
\hline 31 & Hypothetical protein & TK0163 & 46 & 1.8 & 5.60 & 5.6 & 28.74 & 29.7 \\
\hline 32 & Oxidoreductase & TK0845 & 22 & 3.0 & 5.36 & 5.4 & 31.57 & 31.8 \\
\hline 33 & Eukaryotic-type DNA primase & TK1790 & 17 & 2.8 & 6.24 & 6.2 & 40.27 & 40.0 \\
\hline 34 & Inorganic pyrophosphatase & TK1700 & 47 & 1.7 & 4.84 & 4.8 & 20.78 & 22.0 \\
\hline 35 & Acetyltransferase & TK1174 & 31 & 1.8 & 5.98 & 6.0 & 18.79 & 19.1 \\
\hline 36 & Hypothetical protein & TK1584 & 36 & 1.9 & 5.71 & 5.7 & 10.92 & 11.9 \\
\hline 37 & $\begin{array}{l}\text { 2-oxoisovalerate:ferredoxin oxidoreductase, alpha } \\
\text { subunit }\end{array}$ & TK1980 & 26 & 2.1 & 4.97 & 5.0 & 44.37 & 44.5 \\
\hline 38 & Pyridoxine/pyridoxal 5-phosphate biosynthesis protein & TK0217 & 25 & 2.6 & 5.57 & 5.5 & 36.64 & 37.7 \\
\hline 39 & Thermophile-specific fructose-1,6-bisphosphatase & TK2164 & 60 & 2.7 & 5.36 & 5.3 & 41.63 & 41.8 \\
\hline 40 & Serine hydroxymethyltransferase & TK0528 & 41 & 2.0 & 5.80 & 5.2 & 48.20 & 47.3 \\
\hline 41 & Glutamate dehydrogenase & TK1431 & 34 & 1.8 & 5.88 & 5.5 & 47.03 & 47.9 \\
\hline 42 & Deblocking aminopeptidase & TK1177 & 54 & 1.8 & 5.39 & 5.3 & 38.17 & 38.0 \\
\hline 43 & ATPase involved in chromosome partitioning & TK2007 & 36 & 2.2 & 5.71 & 5.6 & 27.61 & 27.5 \\
\hline 44 & Hydrolase & TK2232 & 21 & 2.5 & 5.42 & 5.4 & 24.24 & 24.5 \\
\hline 45 & Peroxiredoxin & TK0537 & 48 & 3.5 & 5.02 & 4.9 & 24.63 & 24.0 \\
\hline 46 & Myo-inositol-1-phosphate synthase & TK2278 & 23 & 2.5 & 5.31 & 5.0 & 42.39 & 43.0 \\
\hline 47 & 2-amino-3-oxobutylrate Co A ligase & TK2217 & 18 & 3.0 & 5.53 & 5.5 & 43.94 & 44.9 \\
\hline 48 & DNA polymerase sliding clamp & TK0535 & 32 & 2.5 & 4.49 & 4.4 & 28.22 & 28.0 \\
\hline 49 & Anthranilate synthase & TK0254 & 14 & 2.2 & 5.20 & 5.6 & 48.51 & 49.5 \\
\hline 50 & Cell division GTPase & TK1421 & 29 & 2.3 & 4.80 & 4.4 & 40.03 & 40.0 \\
\hline 51 & Hydrolase & TK0251 & 14 & 1.9 & 4.91 & 4.2 & 27.41 & 29.4 \\
\hline 52 & Chromosome partitioning protein ParB homologue & TK0378 & 24 & 2.4 & 5.85 & 5.0 & 35.97 & 38.0 \\
\hline 53 & Glyceraldehyde-3-phosphate dehydrogenase & TK0765 & 25 & 2.5 & 5.30 & 5.9 & 37.21 & 36.2 \\
\hline 54 & Distant homolog of phosphate transport system & TK1967 & 26 & 1.6 & 4.58 & 4.0 & 23.99 & 22.0 \\
\hline 55 & ABC-type phosphate transport system & TK1868 & 22 & 2.5 & 5.30 & 5.9 & 28.41 & 30.5 \\
\hline 56 & Serine-glyoxylate aminotransferase & TK1548 & 17 & 2.2 & 5.93 & 6.5 & 42.88 & 44.0 \\
\hline 57 & Hypothetical protein & TK1160 & 42 & 1.9 & 6.84 & 6.5 & 14.79 & 15.5 \\
\hline 58 & $N$-acetyltransferase & TK1054 & 15 & 2.4 & 6.64 & 6.0 & 20.77 & 20.0 \\
\hline 59 & Transcription regulator & TK0126 & 23 & 2.5 & 6.77 & 6.2 & 20.70 & 21.0 \\
\hline
\end{tabular}

a Sequence coverage, ${ }^{\mathrm{b}}$ Theoretical pl, ${ }^{\mathrm{c}}$ Experimental pl, ${ }^{\mathrm{d}}$ theoretical mass ( $\mathrm{kDa}$ ), and ${ }^{\mathrm{e}}$ experimental mass ( $\mathrm{kDa}$ ) of the identified proteins. 
T. kodakarensis KOD1 could grow after aerobic inoculation, at which the cells were initially under oxygen saturation at the cultivation temperature (Kobori et al., 2010). To study the effect of stresses on T. kodakarensis KOD1, the cells were exposed to $95^{\circ} \mathrm{C}, 1 \mathrm{M} \mathrm{NaCl}$, or saturated oxygen condition for $4 \mathrm{~h}$. The effect of the stresses on cells viability was assayed using the most probable number method. The results showed that there were no significant differences in the frequency of viable cells compared to control (Supplementary Figure S1). To better understand the molecular mechanism underlying the responses of $T$. kodakarensis KOD1 to heat, oxidative, and salt stresses, we conducted comparative proteomics assays to identify proteins differentially expressed in this strain based on 2-D gel electrophoresis using cells grown under the stresses for $1 \mathrm{~h}$. The cytosolic proteins were subjected to 2-DE, and MALDI was used to identify the proteins involved in heat, oxidative, and salt responses. Proteins extracted under conditions without any stress were used as a control. The gels (Supplementary Figures S2-S4) were silver stained and subsequently analyzed using PDQuest 7.1. After optimization of the 2-DE gels and image processing, the proteins showing at least 1.5-fold (control reference gel) increased expression were further subjected to mass spectrometry. The experiments were repeated three times, and only the reproducible differences were considered.

Based on the 2-DE gels, we identified 83, 33, and 56 upregulated proteins in response to heat, osmotic, and oxidative stresses, respectively. Among these proteins, 59, 42, and 29 upregulated proteins were identified using MALDI-TOF/MS, and these results are summarized in Tables 1-3 under heat, oxidative, and salt stresses, respectively. The pIs of the protein spots ranged from 4.0 to 6.5 , and the molecular masses ranged from 5.4 to $92.6 \mathrm{kDa}$. A homology-based search using the available protein databases revealed that proteins of T. kodakarensis KOD1 origin as the best results in all cases. The molecular masses and pIs for each protein, estimated from the spot positions on the gels, were compared with those of the homologous proteins retrieved. In most cases, these values were comparable (Tables 1-3).

Among the up-regulated proteins under the three stresses, 27 proteins were up regulated under both heat and oxidative stresses, representing 46 and $53 \%$ of the total proteins under a single stress, and seven proteins were up regulated under both heat and salt stresses (Figure 1; Supplementary Table S2). Only six proteins were present in the catalog of up-regulated proteins in the presence of both oxidative and salt stresses. Moreover, four proteins (TK0108, TK0217, TK0537, and TK1085) were over-expressed under all three stresses. These results suggested that T. kodakarensis KOD1 utilized similar defense mechanisms to a certain extent against heat and oxidative stresses. On the other hand, 29,30 , and 20 proteins were up regulated specifically under heat, oxidative, and salt stress, respectively, (Figure 1; Supplementary Table S2). These results suggested that there were also distinct mechanisms for T. kodakarensis KOD1 to defense against different stresses. For example, TK0189 (OsmC) was overexpressed in response to osmotic stress, but not under heat and oxidative stress (Park et al., 2008).

\section{Functional Assay of the Co-Over-Expressed Proteins under Stresses}

To examine the function of the co-over-expressed proteins, the effects of the overexpression of TK0108, TK0217, TK0537, and TK1085 on the growth of E. coli under different environment stresses were analyzed. After induction by IPTG, the expression of the proteins was checked by SDS-PAGE (data not shown). Cultures of $E$. coli cells either expressing the four proteins or containing the pET28 vector were diluted and spread on different plates. Figure 2A showed that recombinant and control cells have similar growth on LB medium in overnight grown culture. The growth of the strain containing the pET28 vector was inhibited by high temperature treatment or by the addition of a high concentration of $\mathrm{H}_{2} \mathrm{O}_{2}$ and $\mathrm{NaCl}$ to the medium. Whereas, the E. coli expressing TK0108, TK0217, TK0537, and TK1085 displayed the higher tolerance to heat stress. In high oxidative and salinity supplemented medium, the recombinant cells also increased the number of colonies as compared to control cells.

As an additional way to examine the possible function of identified proteins, we used the STRING tool to prepare an interaction map (Figure 2B). As might be expected, TK0537 and TK1085 have the high connectivity (score $>0.80$ ) with proteins involved in oxygen detoxifying. The molecular chaperones displayed connectivity with TK0217. Interestingly, TK0108 showed high connectivity (score $>0.75$ ) with proteins in DNA repair and transcription. These results indicate that the four proteins may contribute to the stress tolerance in different pattern.

\section{Functional Categorization Analysis}

We conducted a GO analysis to characterize protein function. The proteins up-regulated during the three stresses were categorized according to molecular functions and biological processes based on GO classification, using BLAST2GO. GO categories were assigned to all proteins according to molecular functions and biological processes.

The classification of heat stress proteins based on biological processes generated ten different groups (Figure 3A). More than $80 \%$ of the total proteins were classified into three categories: metabolic processes (40\%), cellular processes $(26 \%)$, and single-organism processes (20\%). The classification of oxidative stress proteins based on biological processes generated eight different groups, and more than $80 \%$ of the total proteins were classified into three categories: metabolic processes (38\%), cellular processes $(26 \%)$, and single-organism processes $(22 \%$; Figure 3A). For salt stress proteins, six different groups were generated, and the ratios in metabolic processes, cellular processes, and single-organism processes were 37,27 , and $19 \%$, respectively, (Figure 3A).

The classification according to molecular function showed six different groups of proteins up-regulated in response to heat (Figure 3B), and $94 \%$ of these proteins belonged to either (1) catalytic activity (54\%) or binding activity (40\%). Other categories included transporter activity, enzyme regulator activity, electron carrier activity, and antioxidant activity. Whereas the classification of proteins under oxidative stress yielded five different groups, with $90 \%$ of the proteins belonging 
TABLE 2 | List of up-regulated proteins under oxidative stress in T. kodakarensis KOD1.

\begin{tabular}{|c|c|c|c|c|c|c|c|c|}
\hline No & Protein name & Protein ID & $\operatorname{SC}(100 \%)^{a}$ & Fold change & $\mathbf{p l}^{\mathbf{b}}$ & $\mathrm{pl}^{\mathrm{c}}$ & $M w^{d}$ & Mwe \\
\hline 1 & ABC-type dipeptide transport system & TK1804 & 15 & 1.9 & 4.64 & 4.8 & 92.13 & 92.6 \\
\hline 2 & DNA/RNA repair helicase & TK0928 & 12 & 2.1 & 4.33 & 4.5 & 53.15 & 54.0 \\
\hline 3 & $\begin{array}{l}\text { Thermophile-specific fructose-1,6-bisphosphatase } \\
\text { fructose-1,6-bisphosphatase }\end{array}$ & TK2164 & 15 & 2.6 & 5.36 & 5.4 & 41.63 & 43.5 \\
\hline 4 & Archaeal ATPase & TK1465 & 21 & 3.0 & 6.36 & 6.4 & 53.84 & 54.2 \\
\hline 5 & Zinc-dependent protease & TK0699 & 10 & 2.9 & 5.49 & 5.9 & 53.56 & 54.8 \\
\hline 6 & Thioredoxin reductase & TK2100 & 15 & 3.2 & 5.85 & 5.9 & 35.97 & 37.0 \\
\hline 7 & Ferredoxin oxidoreductase & TK1980 & 18 & 2.7 & 4.97 & 5.0 & 44.40 & 45.4 \\
\hline 8 & Glutamate dehydrogenase & TK1431 & 21 & 2.6 & 5.88 & 5.5 & 46.90 & 47.9 \\
\hline 9 & Glyceraldehyde-3-phosphate dehydrogenase & TK0765 & 26 & 3.4 & 5.96 & 6.4 & 37.21 & 37.8 \\
\hline 10 & Peptide methionine sulphoxide reductase & TK0819 & 21 & 2.2 & 5.04 & 5.6 & 39.09 & 38.3 \\
\hline 11 & Cell division ATPase & TK1421 & 28 & 1.8 & 4.80 & 5.3 & 40.03 & 41.6 \\
\hline 12 & 2-deoxyribose 5-phosphate aldolase & TK2104 & 25 & 1.9 & 5.18 & 5.6 & 24.49 & 25.8 \\
\hline 13 & ATPase & TK0701 & 10 & 2.0 & 4.81 & 4.9 & 31.93 & 31.0 \\
\hline 14 & Transcription regulator & TK1962 & 21 & 2.4 & 5.67 & 5.9 & 22.02 & 23.0 \\
\hline 15 & Hypothetical protein & TK0083 & 41 & 1.8 & 4.23 & 4.6 & 11.67 & 12.0 \\
\hline 16 & Hypothetical protein & TK0361 & 14 & 2.1 & 4.82 & 4.9 & 16.40 & 16.7 \\
\hline 17 & Molydopterin converting factor & TK2118 & 36 & 2.4 & 4.77 & 4.9 & 9.15 & 9.8 \\
\hline 18 & Thermosome alpha subunit & TK0678 & 48 & 3.5 & 4.84 & 4.3 & 59.12 & 59.9 \\
\hline 19 & ABC-type maltodextrin transport system & TK1771 & 15 & 2.5 & 4.56 & 4.4 & 49.44 & 48.5 \\
\hline 20 & Thermosome beta subunit & TK2303 & 36 & 3.3 & 4.86 & 4.3 & 59.13 & 60.4 \\
\hline 21 & Sugar-phosphate nucleotidyltransferase & TK0219 & 19 & 2.1 & 5.15 & 5.2 & 46.80 & 45.8 \\
\hline 22 & Acyl-CoA synthetase & TK0944 & 8 & 2.1 & 5.51 & 5.0 & 51.83 & 50.6 \\
\hline 23 & Hypothetical protein & TK1792 & 28 & 1.6 & 4.83 & 4.9 & 40.20 & 42.2 \\
\hline 24 & Zinc-dependent protease & TK0689 & 31 & 2.3 & 5.20 & 5.3 & 48.52 & 49.7 \\
\hline 25 & Hypothetical protein & TK0443 & 15 & 1.9 & 5.4 & 5.4 & 40.97 & 41.5 \\
\hline 26 & Glycine cleavage system protein & TK1379 & 38 & 2.8 & 5.51 & 5.2 & 55.96 & 56.6 \\
\hline 27 & Methionine synthase II & TK1447 & 12 & 2.1 & 5.90 & 5.5 & 35.25 & 36.2 \\
\hline 28 & Metallophosphoesterase & TK0547 & 19 & 2.1 & 5.22 & 5.6 & 24.12 & 24.8 \\
\hline 29 & Protein disulphide oxidoreductase & TK1085 & 39 & 4.1 & 4.72 & 4.6 & 25.28 & 25.7 \\
\hline 30 & Deblocking aminopeptidase & TK0781 & 31 & 1.8 & 5.46 & 5.9 & 38.27 & 38.6 \\
\hline 31 & Hypothetical protein & TK2125 & 46 & 1.9 & 5.82 & 5.9 & 28.73 & 29.2 \\
\hline 32 & Oxidoreductase & TK0845 & 22 & 3.2 & 5.36 & 5.5 & 31.57 & 32.4 \\
\hline 33 & Eukaryotic-type DNA primase & TK1791 & 17 & 2.4 & 6.24 & 6.5 & 40.27 & 40.9 \\
\hline 34 & Inorganic pyrophosphatase & TK1700 & 47 & 2.1 & 4.84 & 4.2 & 20.78 & 21.3 \\
\hline 35 & Hypothetical protein & TK0108 & 56 & 2.0 & 4.99 & 5.5 & 22.39 & 23.4 \\
\hline 36 & Acetyltransferase & TK1174 & 31 & 2.8 & 5.98 & 6.4 & 18.79 & 18.0 \\
\hline 37 & $\begin{array}{l}\text { Pyridoxine/pyridoxal 5-phosphate biosynthesis } \\
\text { protein protein, SOR/SNZ family biosynthesis }\end{array}$ & TK0217 & 25 & 3.1 & 5.57 & 5.5 & 36.64 & 37.6 \\
\hline 38 & Serine hydroxymethyltransferase & TK0528 & 41 & 2.5 & 5.80 & 5.0 & 48.20 & 47.6 \\
\hline 39 & Ornithine carbamoyltransferase & TK0871 & 28 & 2.4 & 5.76 & 5.0 & 35.02 & 36.0 \\
\hline 40 & ATPase involved in chromosome partitioning & TK2007 & 36 & 2.7 & 5.71 & 5.1 & 27.61 & 26.6 \\
\hline 41 & Hydrolase & TK2232 & 21 & 2.8 & 5.42 & 5.0 & 24.24 & 25.2 \\
\hline 42 & Peroxiredoxin & TK0537 & 48 & 4.8 & 5.02 & 4.8 & 24.63 & 26.5 \\
\hline
\end{tabular}

a Sequence coverage, b Theoretical pl, ${ }^{\mathrm{c}}$ Experimental pl, ${ }^{\mathrm{d}}$ theoretical mass ( $\mathrm{kDa}$ ), and experimental mass ( $\mathrm{kDa}$ ) of the identified proteins.

to either catalytic activity (53\%) or binding activity (37\%; Figure 3B). The salt stress proteins were classified into seven different groups, with $49 \%$ of the proteins belonging to catalytic activity and $32 \%$ of the proteins belonging to binding activity (Figure 3B). The different proteins with catalytic activity were highly represented, suggesting that these proteins might function in metabolic pathways that deserve further attention.

\section{Metabolic Pathway Analysis}

The results of the GO analysis showed that these stresses influenced a variety of cellular processes, particularly metabolic processes (Figure 4). The up-regulated proteins were further analyzed using the KEGG to explore potential metabolic pathway functions. Among these proteins, 30 proteins were associated with specific KEGG pathways. These proteins were involved in 
TABLE 3 | List of up-regulated proteins under salt stress in T. kodakarensis KOD1.

\begin{tabular}{|c|c|c|c|c|c|c|c|c|}
\hline No. & Protein name & Protein ID & $\operatorname{SC}(100 \%)^{a}$ & Fold change & $\mathbf{p} \mathbf{l}^{\mathbf{b}}$ & $\mathrm{pl}^{\mathrm{c}}$ & $M w^{d}$ & Mwe \\
\hline 1 & Thioredoxin reductase & TK2100 & 24 & 3.1 & 5.85 & 6.0 & 39.44 & 38.4 \\
\hline 2 & Xaa-Pro aminopeptidase & TK0967 & 27 & 2.1 & 5.07 & 5.5 & 39.20 & 39.2 \\
\hline 3 & Phosphoribosyl transferase & TK0853 & 21 & 2.8 & 5.40 & 5.8 & 36.24 & 38.2 \\
\hline 4 & Deblocking aminopeptidase & TK1177 & 23 & 2.2 & 5.39 & 5.8 & 38.17 & 39.2 \\
\hline 5 & 2-dehydro-3-deoxyphosphoheptonate aldolase & TK0268 & 25 & 2.8 & 5.28 & 5.5 & 33.43 & 35.4 \\
\hline 6 & Peptide methionine sulphoxide reductase & TK0819 & 28 & 2.1 & 5.29 & 5.1 & 29.25 & 28.2 \\
\hline 7 & Archaeal glucosamine-6-phosphate deaminase & TK1755 & 23 & 1.8 & 5.41 & 5.6 & 36.72 & 36.7 \\
\hline 8 & 2-dehydropantoate 2-reductase & TK1968 & 37 & 2.5 & 4.43 & 4.6 & 34.03 & 34.9 \\
\hline 9 & Pyridoxine/pyridoxal 5-phosphate protein & TK0217 & 25 & 2.8 & 5.57 & 5.1 & 36.64 & 37.6 \\
\hline 10 & Hypothetical protein, conserve, DUF75 & TK1919 & 27 & 1.6 & 5.58 & 5.1 & 26.19 & 28.2 \\
\hline 11 & DNA polymerase sliding clamp & TK0535 & 32 & 2.2 & 4.49 & 4.9 & 28.22 & 29.2 \\
\hline 12 & Inositol-1-monophosphatase & TK0787 & 27 & 2.9 & 5.27 & 5.9 & 27.97 & 26.0 \\
\hline 13 & Metal-dependent phosphohydrolase & TK1944 & 25 & 2.4 & 5.76 & 5.0 & 30.00 & 30.8 \\
\hline 14 & Prephenate dehydrogenase & TK0259 & 38 & 2.6 & 5.29 & 5.9 & 29.25 & 31.3 \\
\hline 15 & Ferredoxin: NADP oxidoreductase & TK1685 & 28 & 3.0 & 5.76 & 5.0 & 32.50 & 33.5 \\
\hline 16 & Protein disulphide oxidoreductase & TK1085 & 39 & 3.2 & 4.72 & 4.0 & 25.28 & 24.3 \\
\hline 17 & Hypothetical protein & TK0108 & 20 & 1.7 & 4.99 & 5.0 & 22.39 & 24.4 \\
\hline 18 & Metal-dependent phosphohydrolase & TK0014 & 45 & 1.9 & 5.15 & 5.9 & 21.24 & 20.2 \\
\hline 19 & Peroxiredoxin & TK0537 & 48 & 4.5 & 5.02 & 5.8 & 24.63 & 22.6 \\
\hline 20 & Acid phosphatase & TK1137 & 30 & 2.4 & 5.90 & 5.0 & 28.25 & 29.3 \\
\hline 21 & Hypothetical protein & TK1561 & 52 & 2.0 & 5.32 & 4.8 & 21.77 & 23.8 \\
\hline 22 & Osmotically inducible protein C (OsmC) & TK0189 & 34 & 3.8 & 5.85 & 5.1 & 15.34 & 13.3 \\
\hline 23 & Transcription regulator & TK0834 & 28 & 2.5 & 6.67 & 6.0 & 22.22 & 23.2 \\
\hline 24 & Peptidyl-prolyl cis-trans isomerase & TK1850 & 39 & 2.8 & 4.32 & 5.0 & 17.54 & 18.5 \\
\hline 25 & Hydrogenase maturation protease & TK2004 & 30 & 2.1 & 4.73 & 4.0 & 17.03 & 18.0 \\
\hline 26 & Predicted nucleic acid-binding protein & TK0066 & 43 & 2.3 & 4.80 & 4.4 & 16.88 & 15.9 \\
\hline 27 & Hypothetical protein & TK1409 & 44 & 1.6 & 4.74 & 4.0 & 9.59 & 10.0 \\
\hline 28 & Hypothetical protein, conserve & TK0783 & 41 & 2.1 & 4.87 & 5.3 & 11.84 & 12.8 \\
\hline 29 & LSU ribosomal protein L7AE & TK1311 & 40 & 2.7 & 5.20 & 5.9 & 13.69 & 14.7 \\
\hline
\end{tabular}

a Sequence coverage, ${ }^{\mathrm{b}}$ Theoretical pl, ${ }^{\mathrm{c}}$ Experimental $\mathrm{pl}{ }^{\mathrm{d}}$ theoretical mass ( $\mathrm{kDa}$ ), and ${ }^{\mathrm{e}}$ experimental mass ( $\mathrm{kDa}$ ) of the identified proteins.

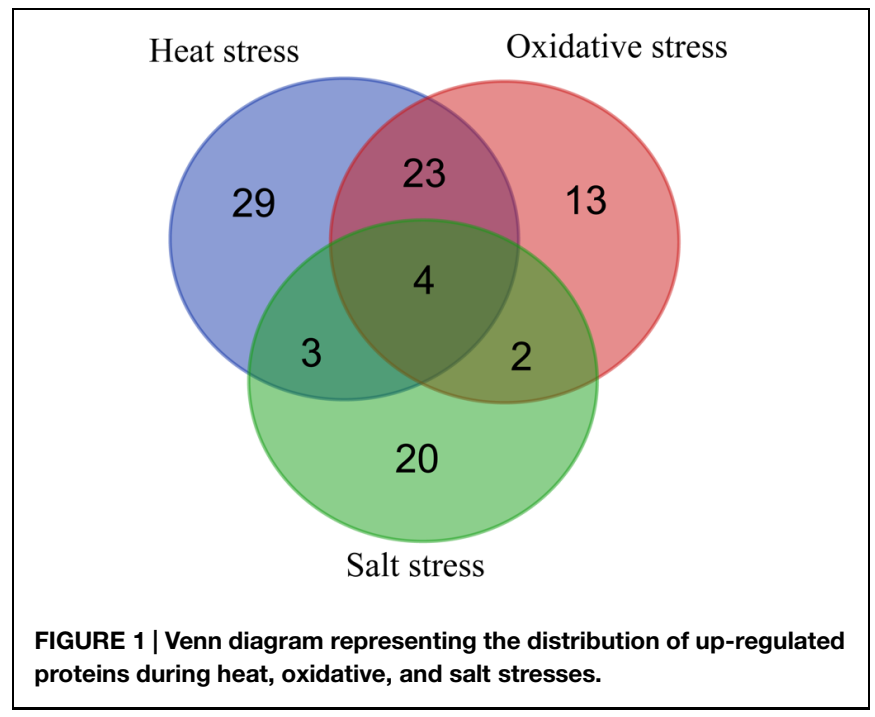

pentose phosphate pathway, glycolysis, amino acids metabolism, the urea cycle, secondary metabolite synthesis, transporter, and electron transfer chain. Two enzymes in gluconeogenic pathway (TK2164 and TK0765) were up regulated under both heat and oxidative stresses. TK1771 involved in carbohydrate uptake was also increased under both heat and oxidative stresses. TK0955 and TK1110 in mannose metabolism were only up regulated under heat stress. TK0254, TK0259, TK0268, TK1379, TK1431, TK1447, and TK2217 that were up-regulated by different stresses may participate in amino acids synthesis. Among them, TK1379, TK1431, and TK1447 were increased under both heat and oxidative stresses. TK0254 and TK2217 were up regulated by only heat stress while TK0268 and TK0259 were increased under salt stress. TK0787 and TK0217 involved in compatible solute synthesis were abundant under salt stress. Interestingly, TK0217 were also up regulated by heat stress. Further function of these enzymes were discussed in the following section.

\section{Discussion}

All living organisms must adapt to changing environmental conditions to survive. The success of Thermococcus largely reflects an ability to survive under extreme conditions. However, these strains are constantly exposed to different stresses. In 
A

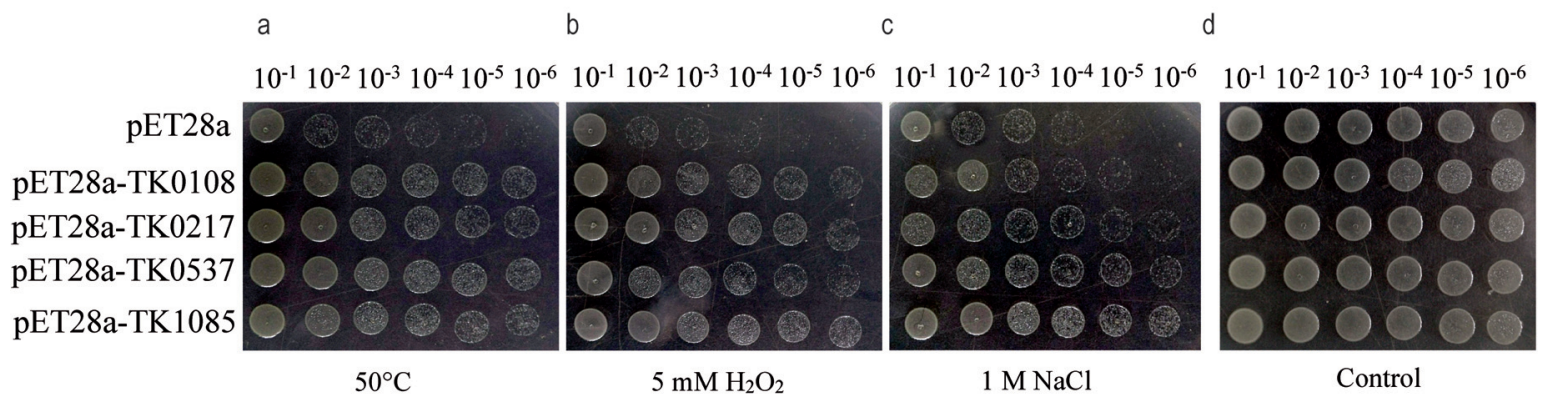

B

a

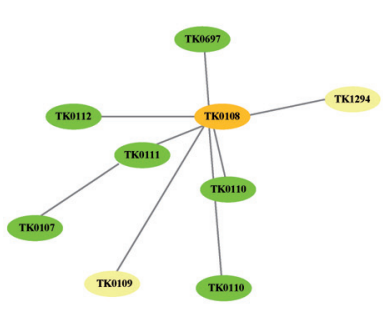

b

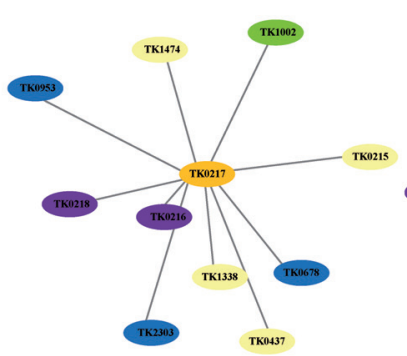

C

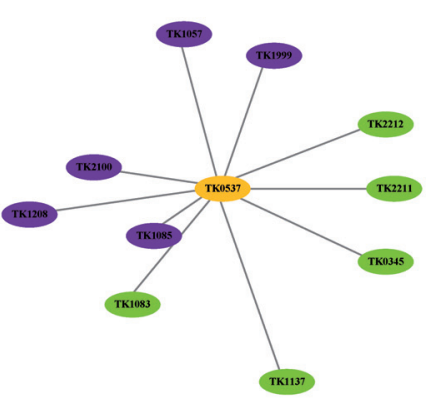

d

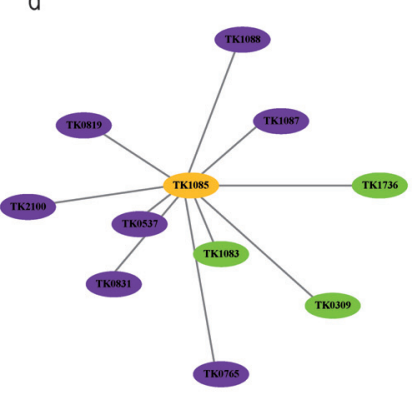

FIGURE 2 | Functional analysis of the co-over-expressed proteins by Agar plate bioassay and protein-protein interaction. (A) TK0108, TK0217, TK0537, and TK1085 confer stress tolerance to Escherichia coli. (a) Growth tolerance to heat stress. E. coli cells expressing the four proteins $(\mathrm{OD} 600=0.5)$ were preheated at $50^{\circ} \mathrm{C}$ for $20 \mathrm{~min}$ and then incubated at $37^{\circ} \mathrm{C}$ for $12 \mathrm{~h}$. Various dilutions $\left(10^{-1}\right.$ to $\left.10^{-6}\right)$ were spotted on LB plates. (b,c) Survival of different strains in response to $\mathrm{H}_{2} \mathrm{O}_{2}$ and $\mathrm{NaCl}$ exposure. IPTG was added to the cultures of $E$. coli cells to induce the expression of recombinant proteins. The cultures were adjusted to OD600 $=0.5,10 \mu \mathrm{L}$ from $10^{-1}$ to $10^{-6}$ dilutions were spotted onto LB plates with $5 \mathrm{mM} \mathrm{H}_{2} \mathrm{O}_{2}$ (b) and $1 \mathrm{M} \mathrm{NaCl}$ (c) and then incubated at $37^{\circ} \mathrm{C}$ for $12 \mathrm{~h}$. (d) The same amount of $E$. coli cells either expressing the four proteins or containing the pET28 vector grown at $37^{\circ} \mathrm{C}$ for $12 \mathrm{~h}$ were used as a control. (B) Predicted protein-protein interaction network, using STRING v9.1, to examine co-expressed proteins (a), the hypothetical protein (TK0108); (b), pyridoxal biosynthesis lyase PdxS (TK0217); (c), peroxiredoxin (TK0537); and (d), protein disulphide oxidoreductase (TK1085)) in heat, oxidative, and salt-stressed Thermococcus kodakarensis KOD1 cells. The graph was constructed in the STRING tools using standard parameters. The proteins that may be involved in oxygen detoxifying are shown in violet and the proteins that may regulate DNA repair and transcription are shown in green. The chaperones are shown in blue. Protein functions were predicted using the software listed in 'Materials and Methods.' the present study, we conducted a proteomics analysis on T. kodakarensis KOD1 to globally identify differences in protein expression under heat, oxidative, and salt stresses. Some proteins, such as thermosome, OsmC, and peroxiredoxin, were overexpressed under the examined stresses. The proteomics data further revealed that many interesting proteins were up regulated and some proteins were co-expressed under different stresses. GO and KEGG pathway analyses indicated that sugar, amino acids, and compatible solutes metabolic pathways were involved. The proteins in transmembrane transport and electron transfer chain were also increased.

Cellular stress is induced through the abrupt disruption of the local cell environment. Cells primarily react to various stresses through a number of specific and well conserved adaptive intracellular signaling pathways to alleviate damage and maintain or re-establish homeostasis, and this process has been collectively referred to as the as cellular stress response (Simmons et al., 2009; Jiang et al., 2011). When different stresses are causally and functionally related, certain degrees of overlap, defined as 'crosstalk', between the respective defense programs are expected (Logemann and Hahlbrock, 2002). Under the three stresses examined, we observed the over-expression of four proteins, including a hypothetical protein (TK0108), pyridoxal biosynthesis lyase PdxS (TK0217), peroxiredoxin (TK0537), and protein disulphide oxidoreductase (TK1085) in Thermococcus (Figure 2). The function of TK0108 remains unknown; however, this protein might bind manganesedependent transcription regulators (TK0107), HAD superfamily hydrolases (TK0110), RNA-binding proteins (TK0111), and elongation factors (TK0112) based on predictions of proteinprotein interactions. Based on the protein interaction prediction, we assumes that TK0108 might regulate transcription activity through binding these enzymes under stress conditions. For the other three proteins, a recent study has shown that peroxiredoxin (TK0537) belongs to a 1-Cys Prx6 subfamily. This enzyme exhibits oligomeric forms with reduced peroxide reductase activity as well as decameric and dodecameric forms that can act as molecular chaperones by protecting 
A

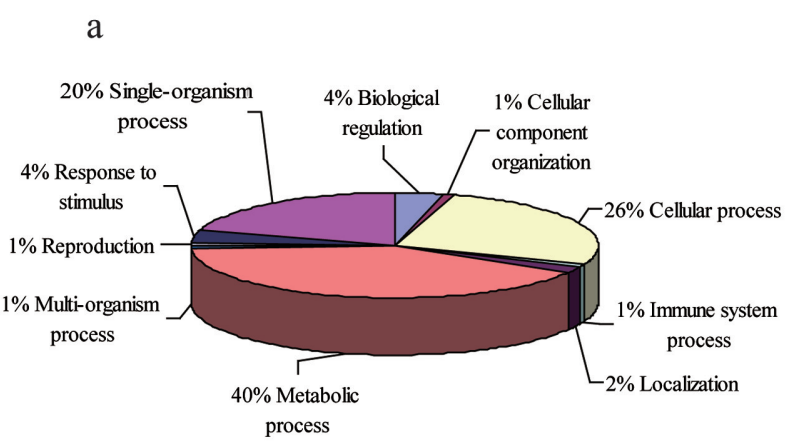

b

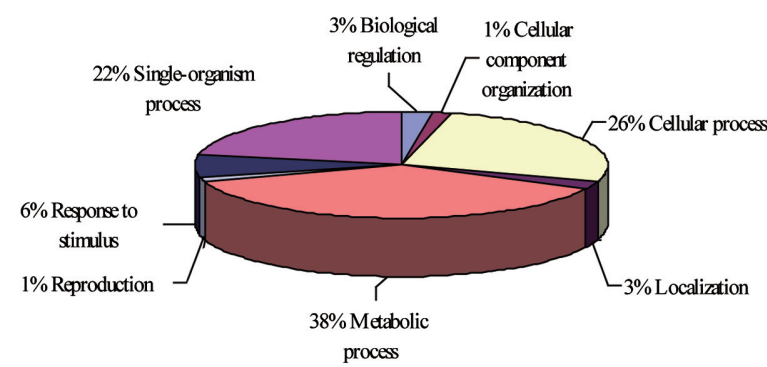

c

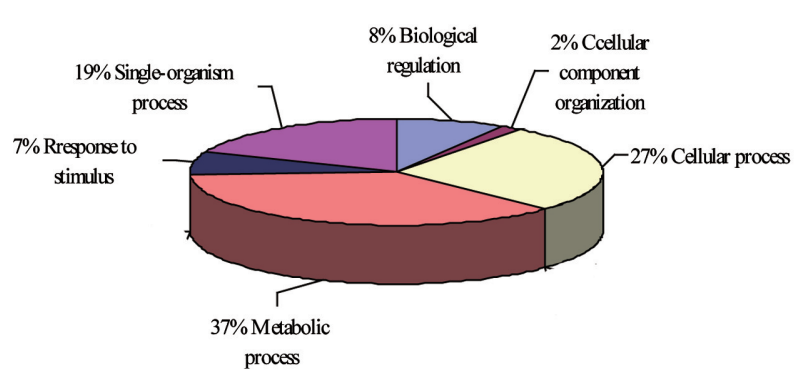

B

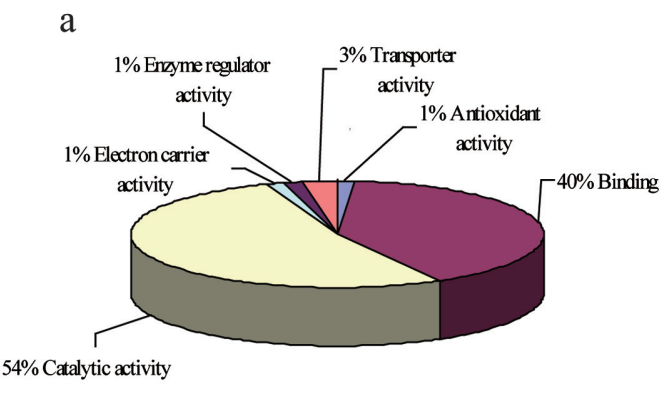

b

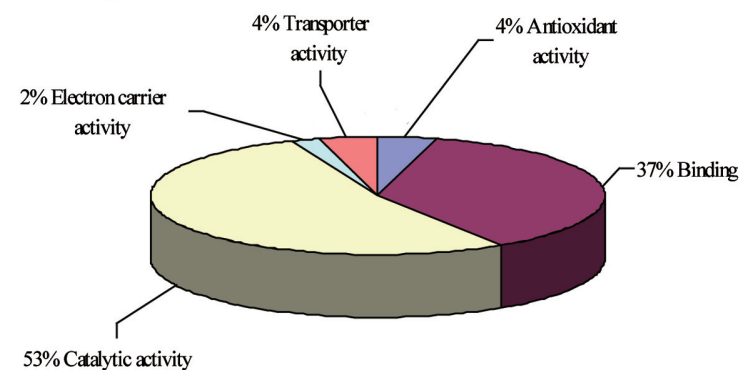

c

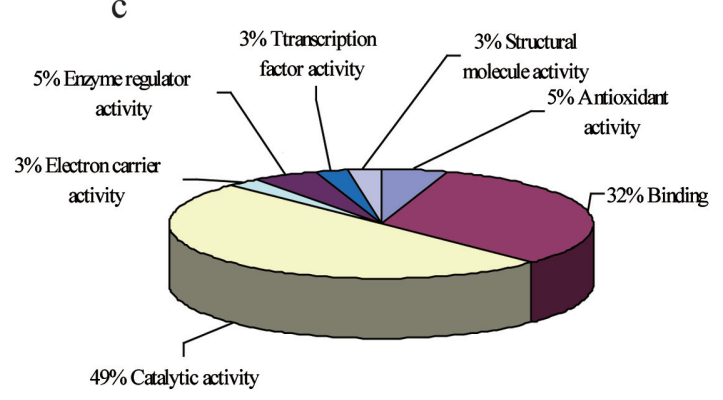

FIGURE 3 | GO enrichment analysis of up-regulated proteins. The GO terms in two biological processes (A) and molecular functions (B) under heat stress (a), oxidative stress (b), and salt stress (c) were analyzed.

both proteins and DNA from heat and oxidative stresses (Lee et al., 2015). Furthermore, peroxiredoxin (TK0537) and protein disulphide oxidoreductase (TK1085) are important enzymes for the regulation of reactive oxygen species (ROS) production and redox balance across human, yeast, and bacterium. Based on predictions of protein-protein interactions, TK0537 and TK1085 interact with one another and with thioredoxin reductase, glutaredoxin-related protein, and ferritinlike protein. TK0217, the pyridoxal biosynthesis lyase PdxS, and TK0126 are essential for the biosynthesis of pyridoxal $5^{\prime}$ phosphate, the active form of vitamin B6 (Matsuura et al.,
2012). Vitamin B6 has long been considered as an enzymatic cofactor. However, it was recently shown that this vitamin is also a potent antioxidant that effectively quenches ROS and is highly important for cellular well-being (Mooney et al., 2009). Increased ROS generation is a common response in cells exposed to stresses; thus, it has been suggested that redox regulation might represent a critical second messenger system upstream of the cell stress signaling network (Kültz, 2005; Jiang et al., 2011), suggesting that these three enzymes are critical factors for cellular stress responses to different stresses. 


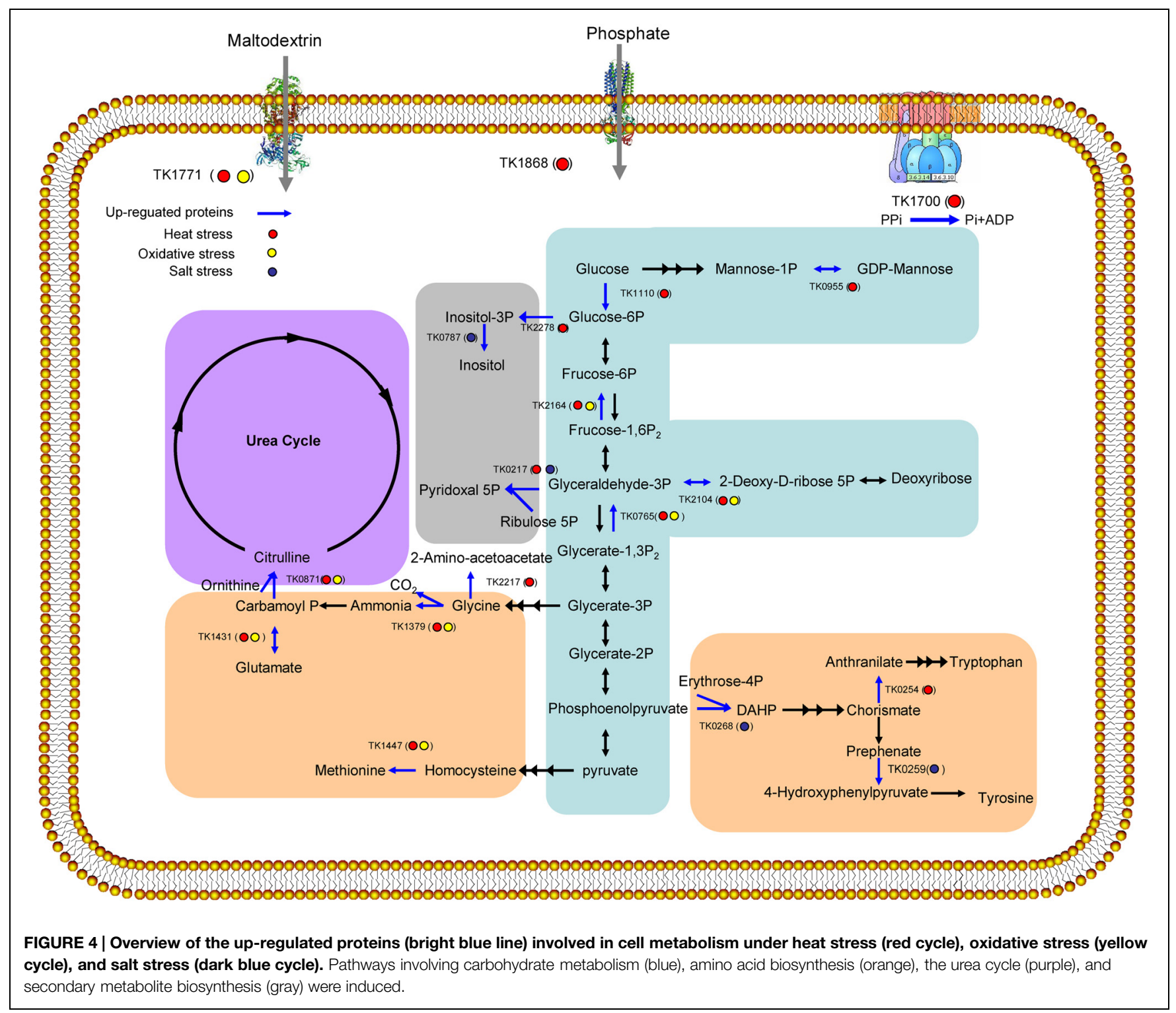

Six enzymes (TK0765, TK0955, TK1110, TK1771, TK2104, and TK2164), involved in carbohydrate metabolism, were abundant in T. kodakarensis KOD1 under the examined stresses (Figure 4). In eukaryotes, it has been proposed that enhanced saccharides uptake and glycolysis protect cells from oxidative stress (Kondoh et al., 2007). TK1771, the maltodextrin-binding periplasmic component of the ABC-type maltodextrin transport system, is in the same operon with TK1774. Recently, we have shown that this TK1774 can produce maltotriose (Guan et al., 2013; Sun et al., 2015). This facts suggests that TK1771 might mediates the uptake of maltotriose. Furthermore, the members of Thermococcus are characterized by the presence of unique, modified variants of classical glycolytic pathways, such as the Embden-Meyerhof-Parnas (EMP) pathway (Brasen et al., 2014). ADP-dependent glucokinase (TK1110), which catalyzes the first step in the EMP pathway to phosphorylate glucose to glucose 6phosphate, was abundantly expressed under heat and oxidative stress conditions. Increasing of glycolytic flux contributes to $\mathrm{NADH}$ production, which can be converted to NADPH by NADH kinase. Additionally, NADPH can be used by cells to prevent against stress (Jia et al., 2010). Interestingly, two gluconeogenic enzymes, fructose-1,6-bisphosphatase (TK2164) and phosphorylating GAP dehydrogenase (TK0765), were also abundantly expressed, potentially redirecting carbon flux away from the EMP pathway. The observed increase in the levels of the gluconeogenic enzymes could signify a boost in the synthesis of glucose-6-phosphate and also favor flux through the ribulose monophosphate pathway, the substitution for the missing pentose phosphate pathway in T. kodakarensis KOD1 to produce NADPH (Orita et al., 2006). Carbon flux could also be redirected through deoxyribose-phosphate aldolase (TK2104) to deoxyribose, the precursor of DNA, suggesting that even under severe stress conditions, equilibrium is maintained with respect to intracellular sugar levels and glycolysis intermediates. 
A few amino acid biosynthesis proteins, such as glutamate dehydrogenase (TK1431), were significantly expressed during heat and oxidative stresses (Figure 4). TK1431 plays a central role in metabolism, as this enzyme is one of the most abundant proteins in Thermococcales cells, exceeding $10 \%$ of the total cytoplasmic protein in T. kodakarensis KOD1 (Altschul et al., 1997). In addition to activity toward Glu, the activity of TK1431 toward Gln, Ala, Val, and Cys has also been detected. Furthermore, TK1431 is responsible for NADH generation in T. kodakarensis KOD1 (Yokooji et al., 2013). Ornithine carbamoyltransferase (TK0871), which was up-regulated under heat and oxidative stresses, might catalyze the conversion of ornithine and carbamoyl phosphate into citrulline in a de novo pathway for arginine synthesis or the detoxifying urea cycle (Legrain et al., 2001). Two additional enzymes (TK0259 and TK0268), involved in tyrosine biosynthesis, were upregulated under salt stress. While TK0254 catalyzing tryptophan biosynthesis from chorismate and TK2217 catalyzing glycine synthesis from glycerate-3P were abundant under heat stress (Figure 4). The up-regulation of these enzymes ensures the supply of amino acids for protein biosynthesis and protection against stress. In addition, amino acids might also play an important role in stress resistance through osmotic adjustment, osmolytes accumulation and ROS detoxification.

In the previous study, responses of Thermococcus and Pyrococcus to stresses have been reported. In both T. kodakarensis and $P$. furiosus, di-myo-inositol phosphate will be accumulated under heat and osmotic stresses (Borges et al., 2010; Esteves et al., 2014). In our study, we found that Inositol-1-monophosphatase (TK0787) and myo-inositol-1-phosphate synthase (TK2278) playing pivotal roles in the biosynthesis of di-myo-inositol phosphate are increased under heat and osmotic stresses, respectively. In the case of oxidative stress, both Thermococcus and Pyrococcus can tolerate high concentration of oxygen (Marteinsson et al., 1997; Kobori et al., 2010; Thorgersen et al., 2012). An NAD(P)H oxidase (TK1481) participates in the oxygen sensitivity the expression of the enzyme is constitutive in T. kodakarensis (Kobori et al., 2010). This result is consistent with

\section{References}

Altschul, S. F., Madden, T. L., Schaffer, A. A., Zhang, J., Zhang, Z., Miller, W., et al. (1997). Gapped BLAST and PSI-BLAST: a new generation of protein database search programs. Nucleic Acids Res. 25, 3389-3402. doi: 10.1093/nar/25.17.3389

Atomi, H., Fukui, T., Kanai, T., Morikawa, M., and Imanaka, T. (2004). Description of Thermococcus kodakaraensis sp. nov., a well studied hyperthermophilic archaeon previously reported as Pyrococcus sp. KOD1. Archaea 1, 263-267. doi: $10.1155 / 2004 / 204953$

Borges, N., Matsumi, R., Imanaka, T., Atomi, H., and Santos, H. (2010). Thermococcus kodakarensis mutants deficient in di-myo-inositol phosphate use aspartate to cope with heat stress. J. Bacteriol. 192, 191-197. doi: 10.1128/jb.01115-09

Bradford, M. M. (1976). A rapid and sensitive method for the quantitation of microgram quantities of protein utilizing the principle of protein-dye binding. Anal. Biochem. 72, 248-254. doi: 10.1016/0003-2697(76) 90527-3

Brasen, C., Esser, D., Rauch, B., and Siebers, B. (2014). Carbohydrate metabolism in Archaea: current insights into unusual enzymes and pathways and their regulation. Microbiol. Mol. Biol. Rev. 78, 89-175. doi: 10.1128/mmbr.00041-13 our research as we do not find the over-expression of the protein in any stress. In Pyrococcus, the expression of SOR and related enzymes which protect aerobes from the toxic effects of oxygen, is also constitutive (Jenney et al., 1999). In the current proteomics result, SOR is not in the list of over-expressed proteins of T. kodakarensis. Interestingly, an alkyl hydroperoxide reductase (PH1217) in P. horikoshii, whose transcription and translation increased by the addition of exogenous oxygen, showed $91 \%$ identity to TK0537. Together with molecular chaperone function of the enzyme (Lee et al., 2015), all of the evidences indicates that TK0537 plays several roles in response to stress.

In the present study, we used 2-D gel electrophoresis and MALDI-TOF/MS in a proteomics approach to obtain insight into the intricate mechanisms of T. kodakarensis KOD1 for survival under heat, oxidative, and salt stresses. Herein, we identified 92 differentially expressed proteins belonging to major processes, including carbohydrate and amino acid biosynthesis, protein folding, and cell redox homeostasis. Most of the proteomics studies under stress have been performed in bacteria and eukaryotes. In the present study, we conducted a proteomics analysis involving Archaea to improve our current understanding of the unique mechanisms in Archaea and explore the evolutionary relationships of stress responses among Archaea, Bacteria, and Eukarya.

\section{Acknowledgments}

This work was supported by the Fund of Research Promotion Program (Gyeongsang National University, 2012) and Natural Science Foundation of China (31201485).

\section{Supplementary Material}

The Supplementary Material for this article can be found online at: http://journal.frontiersin.org/article/10.3389/fmicb. 2015.00605

Chong, P. K., and Wright, P. C. (2005). Identification and characterization of the Sulfolobus solfataricus P2 proteome. J. Proteome Res. 4, 1789-1798. doi: $10.1021 / \mathrm{pr} 0501214$

Conesa, A., and Gotz, S. (2008). Blast2GO: a comprehensive suite for functional analysis in plant genomics. Int. J. Plant Genomics 2008, 619832. doi: $10.1155 / 2008 / 619832$

Danno, A., Fukuda, W., Yoshida, M., Aki, R., Tanaka, T., Kanai, T., et al. (2008). Expression profiles and physiological roles of two types of prefoldins from the hyperthermophilic archaeon Thermococcus kodakaraensis. J. Mol. Biol. 382, 298-311. doi: 10.1016/j.jmb.2008.07.032

Edgcomb, V., Molyneaux, S., Böer, S., Wirsen, C., Saito, M., Atkins, M., et al. (2007). Survival and growth of two heterotrophic hydrothermal vent archaea, Pyrococcus strain GB-D and Thermococcus fumicolans, under low $\mathrm{pH}$ and high sulfide concentrations in combination with high temperature and pressure regimes. Extremophiles 11, 329-342. doi: 10.1007/s00792-006-0043-0

Esteves, A. M., Chandrayan, S. K., Mcternan, P. M., Borges, N., Adams, M. W., and Santos, H. (2014). Mannosylglycerate and di-myo-inositol phosphate have interchangeable roles during adaptation of Pyrococcus furiosus to heat stress. Appl. Environ. Microbiol. 80, 4226-4233. doi: 10.1128/aem. 00559-14 
Feder, M. E., and Hofmann, G. E. (1999). Heat-shock proteins, molecular chaperones, and the stress response: evolutionary and ecological physiology. Annu. Rev. Physiol. 61, 243-282. doi: 10.1146/annurev.physiol.61.1.243

Franceschini, A., Szklarczyk, D., Frankild, S., Kuhn, M., Simonovic, M., Roth, A., et al. (2013). STRING v9.1: protein-protein interaction networks, with increased coverage and integration. Nucleic Acids Res. 41, D808-D815. doi: 10.1093/nar/gks1094

Guan, Q., Guo, X., Han, T., Wei, M., Jin, M., Zeng, F., et al. (2013). Cloning, purification and biochemical characterisation of an organic solvent-, detergent, and thermo-stable amylopullulanase from Thermococcus kodakarensis KOD1. Process. Biochem. 48, 878-884. doi: 10.1016/j.procbio.2013.04.007

Hileman, T. H., and Santangelo, T. J. (2012). Genetics techniques for Thermococcus kodakarensis. Front. Microbiol. 3:195. doi: 10.3389/fmicb.2012.00195

Izumi, M., Fujiwara, S., Takagi, M., Fukui, K., and Imanaka, T. (2001). Two kinds of archaeal chaperonin with different temperature dependency from a hyperthermophile. Biochem. Biophys. Res. Commun. 280, 581-587. doi: 10.1006/bbrc.2000.4154

Jenney, F. E., Verhagen, M. F. J. M., Cui, X., and Adams, M. W. W. (1999). Anaerobic microbes: oxygen detoxification without superoxide dismutase. Science 286, 306-309. doi: 10.1126/science.286.5438.306

Jia, B., Lee, S., Pham, B., Liu, J., Pan, H., Zhang, S., et al. (2010). Oxidized NADH oxidase inhibits activity of an ATP/NAD kinase from a thermophilic archaeon. Protein J. 29, 609-616 doi: 10.1007/s10930-010-9284-y

Jiang, F., Zhang, Y., and Dusting, G. J. (2011). NADPH oxidase-mediated redox signaling: roles in cellular stress response, stress tolerance, and tissue repair. Pharmacol. Rev. 63, 218-242. doi: 10.1124/pr.110.002980

Kanehisa, M., and Goto, S. (2000). KEGG: kyoto encyclopedia of genes and genomes. Nucleic Acids Res. 28, 27-30. doi: 10.1093/nar/28.1.27

Kawakami, R., Sakuraba, H., Kamohara, S., Goda, S., Kawarabayasi, Y., and Ohshima, T. (2004). Oxidative stress response in an anaerobic hyperthermophilic archaeon: presence of a functional peroxiredoxin in Pyrococcus horikoshii. J. Biochem. 136, 541-547. doi: 10.1093/jb/mvh157

Kobori, H., Ogino, M., Orita, I., Nakamura, S., Imanaka, T., and Fukui, T. (2010). Characterization of NADH oxidase/NADPH polysulfide oxidoreductase and its unexpected participation in oxygen sensitivity in an anaerobic hyperthermophilic archaeon. J. Bacteriol. 192, 5192-5202. doi: 10.1128/jb.00235-10

Kondoh, H., Lleonart, M. E., Bernard, D., and Gil, J. (2007). Protection from oxidative stress by enhanced glycolysis; a possible mechanism of cellular immortalization. Histol. Histopathol. 22, 85-90.

Kültz, D. (2003). Evolution of the cellular stress proteome: from monophyletic origin to ubiquitous function. J. Exp. Biol. 206, 3119-3124. doi: $10.1242 /$ jeb.00549

Kültz, D. (2005). Molecular and evolutionary basis of the cellular stress response. Annu. Rev. Physiol. 67, 225-257. doi: 10.1146/annurev.physiol.67.040403.103635

Kwon, S., Kang, S., Park, S.-H., Kim, Y., Choi, J.-S., Lee, J.-H., et al. (2009). Proteomic characterization of the sulfur-reducing hyperthermophilic archaeon Thermococcus onnurineus NA1 by 2-DE/MS-MS. Extremophiles 13, 379-387. doi: 10.1007/s00792-008-0220-4

Lee, S., Jia, B., Liu, J., Pham, B. P., Kwak, J. M., Xuan, Y. H., et al. (2015). A 1Cys peroxiredoxin from a thermophilic archaeon moonlights as a molecular chaperone to protect protein and DNA against stress-induced damage. PLoS ONE 10:e0125325. doi: 10.1371/journal.pone.0125325

Legrain, C., Villeret, V., Roovers, M., Tricot, C., Clantin, B., Van Beeumen, J., et al. (2001). "[20] Ornithine carbamoyltransferase from Pyrococcus furfosus," in Methods in Enzymology, eds R. M. K. Michael and W. W. Adams (Waltham, MA: Academic Press), 227-235.

Letunic, I., Doerks, T., and Bork, P. (2015). SMART: recent updates, new developments and status in 2015. Nucleic Acids Res. 43, D257-D260. doi: 10.1093/nar/gku949

Logemann, E., and Hahlbrock, K. (2002). Crosstalk among stress responses in plants: pathogen defense overrides UV protection through an inversely regulated ACE/ACE type of light-responsive gene promoter unit. Proc. Natl. Acad. Sci. U.S.A. 99, 2428-2432. doi: 10.1073/pnas.042692199

Marteinsson, V. T., Moulin, P., Birrien, J., Gambacorta, A., Vernet, M., and Prieur, D. (1997). Physiological responses to stress conditions and barophilic behavior of the hyperthermophilic vent Archaeon Pyrococcus abyssi. Appl. Environ. Microbiol. 63, 1230-1236.

Matsuura, A., Yoon, J., Yoon, H.-J., Lee, H., and Suh, S. (2012). Crystal structure of pyridoxal biosynthesis lyase PdxS from Pyrococcus horikoshii. Mol. Cells 34, 407-412. doi: 10.1007/s10059-012-0198-8

Mooney, S., Leuendorf, J.-E., Hendrickson, C., and Hellmann, H. (2009). Vitamin B6: a long known compound of surprising complexity. Molecules 14, 329-351. doi: 10.3390/molecules14010329

Morikawa, M., Izawa, Y., Rashid, N., Hoaki, T., and Imanaka, T. (1994). Purification and characterization of a thermostable thiol protease from a newly isolated hyperthermophilic Pyrococcus sp. Appl. Environ. Microbiol. 60, 4559-4566.

Orita, I., Sato, T., Yurimoto, H., Kato, N., Atomi, H., Imanaka, T., et al. (2006). The ribulose monophosphate pathway substitutes for the missing pentose phosphate pathway in the archaeon Thermococcus kodakaraensis. J. Bacteriol. 188, 4698-4704. doi: 10.1128/JB.00492-06

Park, S.-C., Pham, B. P., Van Duyet, L., Jia, B., Lee, S., Yu, R., et al. (2008). Structural and functional characterization of osmotically inducible protein $\mathrm{C}$ (OsmC) from Thermococcus kodakaraensis KOD1. BBA-Proteins Proteom. Biochim. Biophys. Acta 1784, 783-788. doi: 10.1016/j.bbapap.2008.02.002

Reed, C. J., Lewis, H., Trejo, E., Winston, V., and Evilia, C. (2013). Protein adaptations in archaeal extremophiles. Archaea 2013, 14. doi: $10.1155 / 2013 / 373275$

Roy, A., Kucukural, A., and Zhang, Y. (2010). I-TASSER: a unified platform for automated protein structure and function prediction. Nat. Protoc. 5, 725-738. doi: 10.1038/nprot.2010.5

Shannon, P., Markiel, A., Ozier, O., Baliga, N. S., Wang, J. T., Ramage, D., et al. (2003). Cytoscape: a software environment for integrated models of biomolecular interaction networks. Genome Res. 13, 2498-2504. doi: 10.1101/gr.1239303

Simmons, S. O., Fan, C.-Y., and Ramabhadran, R. (2009). Cellular stress response pathway system as a sentinel ensemble in toxicological screening. Toxicol. Sci. 111, 202-225. doi: 10.1093/toxsci/kfp140

Sun, Y., Lv, X., Li, Z., Wang, J., Jia, B., and Liu, J. (2015). Recombinant cyclodextrinase from Thermococcus kodakarensis KOD1: expression, purification, and enzymatic characterization. Archaea 2015:397924. doi: $10.1155 / 2015 / 397924$

Thorgersen, M. P., Stirrett, K., Scott, R. A., and Adams, M. W. (2012). Mechanism of oxygen detoxification by the surprisingly oxygen-tolerant hyperthermophilic archaeon, Pyrococcus furiosus. Proc. Natl. Acad. Sci. U.S.A. 109, 18547-18552. doi: 10.1073/pnas.1208605109

Yokooji, Y., Sato, T., Fujiwara, S., Imanaka, T., and Atomi, H. (2013). Genetic examination of initial amino acid oxidation and glutamate catabolism in the hyperthermophilic archaeon Thermococcus kodakarensis. J. Bacteriol. 195, 1940-1948. doi: 10.1128/jb.01979-12

Yun, S. H., Lee, Y. G., Choi, C.-W., Lee, S.-Y., and Kim, S. I. (2014). Proteomic exploration of extremophiles. Curr. Biotechnol. 3, 87-99. doi: $10.2174 / 22115501113026660040$

Conflict of Interest Statement: The authors declare that the research was conducted in the absence of any commercial or financial relationships that could be construed as a potential conflict of interest.

Copyright (C) 2015 Jia, Liu, Van Duyet, Sun, Xuan and Cheong. This is an open-access article distributed under the terms of the Creative Commons Attribution License (CC BY). The use, distribution or reproduction in other forums is permitted, provided the original author(s) or licensor are credited and that the original publication in this journal is cited, in accordance with accepted academic practice. No use, distribution or reproduction is permitted which does not comply with these terms. 